\title{
A COMPARATIVE STUDY OF CAUDAL BLOCK AND ULTRASOUND-GUIDED TRANSVERSUS ABDOMINIS PLANE BLOCK WITH LEVOBUPIVACAINE AND DEXAMETHASONE AS ADDITIVE IN EXTRAPERITONEAL LOWER ABDOMINAL SURGERIES IN PEDIATRICS
}

\author{
SANDHYA GHODKE ${ }^{1}$, MADHAVI RAVINDRA ${ }^{2}$, HIREMATH RN ${ }^{3}$ \\ ${ }^{1}$ Department of Anaesthesiology, Rainbow Children Hospital, Bengaluru, Karnataka, India. ${ }^{2}$ Department of Paediatric Anaesthesia, Indira \\ Gandhi Institute of Child Health, Bengaluru, Karnataka, India. ${ }^{3}$ Public health Specialist, Bangalore, India. Email: drshekar80@gmail.com
}

Received: 10 March 2021, Revised and Accepted: 05 June 2021

ABSTRACT

Objective: The objective of the study was to evaluate the efficacy of ultrasound-guided transversus abdominis plane (TAP) block versus caudal block for post-operative analgesia with levobupivacaine and dexamethasone as additive in extraperitoneal lower abdominal surgeries in pediatrics as there is no available literature showing the same.

Methods: This is a randomized control study carried out between two groups among 50 children (1-8 years of age), both sexes, posted for elective extraperitoneal lower abdominal surgeries after taking informed consent from parents. Fifty children were randomly allocated into two groups, 25 in each group. Caudal epidural (CE) group received general anesthesia and caudal block with $1 \mathrm{ml} / \mathrm{kg}$ of $0.2 \%$ levobupivacaine and $0.1 \mathrm{mg} / \mathrm{kg}$ dexamethasone. TAP group received general anesthesia and ultrasound-guided TAP block with $0.5 \mathrm{ml} / \mathrm{kg}$ of $0.2 \%$ levobupivacaine and $0.1 \mathrm{mg} / \mathrm{kg}$ dexamethasone. Data were collected by means of pre-designed format with pre-/post-operative assessment with standardized scores.

Results: The mean age of the patients was 4.84 (SD=2.29). Mean face, legs, activity, cry, and consolability score was low and non-significant before shifting the patient ( $<2 \mathrm{~h}$ post-operative [post-op]) in both the groups. Thereafter from 2 to $12 \mathrm{~h}$, the mean score increased to 4.92 (SD=2.72) in the CE group and 2.92 $(\mathrm{SD}=2.17$ ) in the TAP group and the difference was statistically significant at $2 \mathrm{~h}, 4 \mathrm{~h}, 6 \mathrm{~h}$, and $12 \mathrm{~h}$ postoperatively. Mean time to rescue analgesia in the CE group was $4.96 \mathrm{~h}(\mathrm{SD}=4.32)$ and $5.52 \mathrm{~h}(\mathrm{SD}=7.53)$ in the TAP group and difference was statistically significant $(\mathrm{p}=0.000)$. Mean total rescue analgesic requirement for the CE and TAP groups was $298.40 \mathrm{mg}(\mathrm{SD}=170.70)$ and $111.40 \mathrm{mg}(\mathrm{SD}=138.81)$ and the difference was also significant. Post-operative complications such as urinary retention and motor blockade were seen in $28 \%$ of CE patients, while none of the patients experienced post-operative nausea/vomiting.

Conclusions: Our study showed significant increase in duration of post-operative analgesia among TAP patients with reduced requirement of rescue analgesics and lesser post-operative complications as compared to CE patients

Implications: Improved post-operative analgesia with lesser complications in TAP patients.

Keywords: Ultrasound-guided transversus abdominis plane block, Caudal block, Pediatric extra-abdominal surgeries.

(C) 2021 The Authors. Published by Innovare Academic Sciences Pvt Ltd. This is an open access article under the CC BY license (http://creativecommons.org/ licenses/by/4.0/) DOI: http://dx.doi.org/10.22159/ajpcr.2021v14i6.41386. Journal homepage: https://innovareacademics.in/journals/index.php/ajpcr

\section{INTRODUCTION}

Inguinal hernia repair, hydrocelectomy, and orchidopexy are commonly performed surgical procedures in children. Post-operative pain if poorly controlled leads to adverse physiological responses and chronic adverse effects such as delayed long-term recovery, chronic pain, and harmful psychological impact on young [1]. Post-operative pain control is usually provided with a single-shot caudal block. Intra- and postoperative analgesia by effective use of caudal block has been established over the years by many $[2,3]$. However, in recent times, trend has shifted toward the use peripheral nerve blockade due to lower incidences of adverse effects as compared with neuraxial techniques [4].

The transversus abdominis plane (TAP) block is a relatively simple technique that provides myocutaneous anesthesia that, as part of a multimodal analgesic treatment, may be useful in the prevention and treatment of parietal post-operative pain, especially in lower abdominal surgeries. As compared to subarachnoid opioids, TAP block has fewer side effects and the ease and accuracy of administration under ultrasound guidance [5]. Till date, there is lack of data and literature in pediatrics regarding comparison of ultrasound-guided TAP block and caudal block in terms of duration of post-operative analgesia. The aim of this randomized control study was to evaluate the efficacy of TAP block versus caudal block for post-operative analgesia after extraperitoneal lower abdominal surgeries in pediatrics.

\section{METHODS}

This was an observational and longitudinal study among children of $1-8$ years of age. Sample size was 50 children who were posted for elective extraperitoneal lower abdominal surgeries. Informed consent was taken from their parents and children were randomly allocated into two groups, 25 in each group.

Caudal epidural (CE) group received general anesthesia and caudal block with $1 \mathrm{ml} / \mathrm{kg}$ of $0.2 \%$ levobupivacaine and $0.1 \mathrm{mg} / \mathrm{kg}$ dexamethasone.

TAP block group received general anesthesia and ultrasound-guided TAP block with $0.5 \mathrm{ml} / \mathrm{kg}$ of $0.2 \%$ levobupivacaine and $0.1 \mathrm{mg} / \mathrm{kg}$ dexamethasone. Children between 1 and 8 years of age belonging to ASA I and II posted for elective extraperitoneal lower abdominal surgeries in a tertiary level pediatric hospital in South India during the study duration and satisfy selection criteria were included for the study. Children with a history of renal, hepatic, cardiac or neurological conditions, any history of allergic reactions to local anesthetics, and history of bleeding diathesis, coagulopathy were excluded from the study.

After taking proper consent, all patients were pre-medicated with injection (inj) midazolam $0.05 \mathrm{mg} / \mathrm{kg}$ intravenous (IV) and induced with $2-3 \mathrm{mg} / \mathrm{kg}$ of IV propofol and fentanyl $2 \mathrm{mcg} / \mathrm{kg}$ IV before insertion of appropriate size laryngeal mask airway. 
Group CE (active comparator) received caudal block with $1 \mathrm{ml} / \mathrm{kg}$ of $0.2 \%$ levobupivacaine and $0.1 \mathrm{mg} / \mathrm{kg}$ dexamethasone (preservative free). The patients were positioned in the left lateral position and under all aseptic precautions, caudal block was performed with $22 \mathrm{G}$ short bevel needle after negative aspiration of blood and cerebrospinal fluid.

Group TAP received ultrasound-guided TAP block with $0.5 \mathrm{ml} / \mathrm{kg}$ of $0.2 \%$ levobupivacaine and $0.1 \mathrm{mg} / \mathrm{kg}$ dexamethasone (preservative free). The patients were placed supine and the abdomen is exposed between the costal margin and iliac crest. Following skin and transducer preparation, under ultrasound guidance using a linear ultrasound probe of $8-13 \mathrm{MHz}$ a $22 \mathrm{G}$ short bevel needle/Stimuplex needle is advanced in-plane with the transducer into the neurofascial plane between internal oblique and transverses abdominis muscle. After confirming the position under vision, local anesthetic was administered on the operative side.

Maintenance of anesthesia was done with 02 + Air + Isoflurane. Inj. Ondansetron $(0.1 \mathrm{mg} / \mathrm{kg} \mathrm{IV})$ was given as antiemetic prophylaxis to all patients. Ringer lactate (RL) was used as maintenance fluid during the perioperative period. Standard hemodynamic and respiratory parameters were monitored before induction, after induction, and throughout the perioperative period. Measured parameters were divided into primary and secondary outcome measures. Primary outcome measure was the time for first analgesic request in the first $24 \mathrm{~h}$ post-surgery. Secondary outcome measures included total paracetamol consumption till $24 \mathrm{~h}$ post-operative, pain score in post-anesthetic care unit (PACU) and ward, sedation score in PACU and ward, complications such as urinary retention, post-operative nausea/vomiting, and motor blockade in PACU and in ward.

Pain assessment was done using face, legs, activity, cry, and consolability (FLACC) Behavioral Pain Assessment Scale, where minimum score is 0 and maximum score is 10 , at the PACU in the immediate post-operative period and before shifting the patient to the ward, thereafter in the ward at 2, 4, 6, 12, and $24 \mathrm{~h}$ after surgery. Inj. Paracetamol $15 \mathrm{mg} / \mathrm{kg}$ IV was used as the rescue analgesic in the hospital when the FLACC Behavioral Pain Assessment Scale score was found $>3$. Level of sedation was assessed using University of Michigan Sedation Scale where minimum score is 0 and maximum score is 4 . Post-operative nausea/ vomiting was assessed with numerical score with minimum score of 0 and maximum score is 4 . Assessment of motor blockade was done using Bromage score where 0 is the minimum and 3 is the maximum score. Children were discharged from the ward once the guidelines for safe discharge after ambulatory surgery were fulfilled. Data were collected by means of pre-designed format with pre-/post-operative assessment with standardized scores.

\section{RESULTS}

The data collected were analyzed using STATA 13 version IC. Quantitative data such as mean age, weight, blood pressure, heart rate, and respiratory rate were analyzed and expressed as mean and standard deviation. Qualitative data were expressed in frequency and percentages. Chi-square test was applied to test for differences in proportion of patients with significant analgesic relief between the study and control groups. Repeated measures of analysis of variance are used to compare and test for any significant variations in parameters measured overtime between the study and control groups. p-value of 0.05 was taken as statistically significant.

Demographic data obtained included age, gender, weight, diagnosis, surgical procedure, and duration of surgical procedure. The mean age of the patients was $4.84(\mathrm{SD}=2.29)$.

As per Table 1, mean FLACC score was low and non-significant before shifting the patient ( $<2 \mathrm{~h}$ post-operative) in both the groups. Thereafter from 2 to $12 \mathrm{~h}$, the mean score increased to $4.92(\mathrm{SD}=2.72)$ in the $\mathrm{CE}$ group and $2.92(\mathrm{SD}=2.17)$ in the TAP group and the difference was statistically significant at $2 \mathrm{~h}, 4 \mathrm{~h}, 6 \mathrm{~h}$, and $12 \mathrm{~h}$ postoperatively.
Table 1: Mean FLACC scores and standard deviation of both groups

\begin{tabular}{llll}
\hline $\begin{array}{l}\text { Post-operative } \\
\text { time (h) }\end{array}$ & $\begin{array}{l}\text { Group TAP } \\
(\mathbf{n = 2 5 )}\end{array}$ & $\begin{array}{l}\text { Group caudal } \\
(\mathbf{n = 2 5})\end{array}$ & p-value \\
\hline 0 & $0.00 \pm 0.00$ & $0.00 \pm 0.00$ & $\mathrm{NA}$ \\
Before shifting & $0.00 \pm 0.00$ & $0.52 \pm 1.47$ & 0.20 \\
At 2 h & $0.00 \pm 0.00$ & $1.68 \pm 2.13$ & $0.0009 \#$ \\
At $4 \mathrm{~h}$ & $0.12 \pm 0.60$ & $3.56 \pm 2.70$ & $0.0000 \#$ \\
At $6 \mathrm{~h}$ & $1.72 \pm 1.92$ & $3.72 \pm 2.65$ & $0.0468^{*}$ \\
At $12 \mathrm{~h}$ & $2.92 \pm 2.17$ & $4.92 \pm 2.72$ & $0.0163^{*}$ \\
At 24 h & $2.96 \pm 1.24$ & $4.28 \pm 2.44$ & 0.1762 \\
\hline
\end{tabular}

$\left({ }^{*}\right)$ : Significant difference between group TAP and group caudal $(\mathrm{p}<0.05)$, (\#): Highly significant difference between group TAP and group caudal $(\mathrm{p}<0.00)$,

NA: Not applicable, N: Number of patients, TAP: Transversus abdominis plane, FLACC: Face, legs, activity, cry, and consolability

As shown in Table 2, mean time to rescue analgesia in the CE group was $4.96 \mathrm{~h}(\mathrm{SD}=4.32)$ and $5.52 \mathrm{~h}(\mathrm{SD}=7.53)$ in the TAP group and difference was statistically significant $(\mathrm{p}=0.000)$. Mean total rescue analgesic requirement for the $\mathrm{CE}$ and TAP groups was $298.40 \mathrm{mg}$ ( $\mathrm{SD}=170.70$ ) and $111.40 \mathrm{mg}(\mathrm{SD}=138.81)$ and the difference was also significant.

Post-operative complications such as urinary retention and motor blockade, respectively, were seen in $28-20 \%$ of caudal group patients, while none of the patients experienced post-operative nausea/vomiting (Fig. 1).

\section{DISCUSSION}

Initial experience with ultrasound-guided TAP block demonstrated efficacy of the echo-guided technique in different surgical procedures such as cesarean section, appendicectomy, laparoscopic cholecystectomy, and infraumbilical surgery in adult and pediatric patients. Recently, published clinical trials suggest that TAP block may represents an effective alternative to epidural anesthesia but further studies in larger population are necessary.

TAP block was found to increase analgesic consumption with low thoracic epidural analgesia (TEA) in ischemic heart disease patients after abdominal laparotomy [6]. Others found comparable results between continuous TAP technique and epidural analgesia regarding pain, analgesic use, and satisfaction after abdominal surgery [7]. The TAP block affords effective analgesia with opioid-sparing effects, technical simplicity, and long duration of action. Some disadvantages include the need for bilateral block for midline incisions and absence of effectiveness for visceral pain [8]. TAP block has been associated with good pain relief and decreased intraoperative and post-operative opioids requirements after laparoscopic surgery [9]. The analgesic efficacy of the TAP block has been demonstrated in prospective randomized trials compared with placebo, in different surgical procedures such as abdominal surgery, hysterectomy, retropubic prostatectomy, cesarean section, laparoscopic cholecystectomy, and appendicectomy [9-14]. All these studies have reported superiority of the TAP block in terms of reduction in visual analog scale scores and morphine consumption.

TAP block has many potential advantages and drawbacks. It is a simple and effective analgesic technique, especially for surgeries, where the pain is mainly parietal. Furthermore, it is a good alternative analgesic technique when a neuraxial block is contraindicated. However, it is not useful in bilateral conditions [15]

CE analgesia is a popular and reliable technique in lower abdominal surgeries in children [16]. In our study, we found that caudal and TAP blocks in children undergoing day-care unilateral lower abdominal surgeries have comparable time to first analgesic request and postoperative pain scores. The mean FLACC score was low and insignificant in both the groups in initial couple of hours, however, the mean score was comparatively higher (4.92 [SD=2.72]) in the CE group from 2 to 
Table 2: Comparison between group TAP and group caudal

\begin{tabular}{|c|c|c|c|}
\hline Parameters & $\begin{array}{l}\text { Group TAP } \\
(n=25)\end{array}$ & $\begin{array}{l}\text { Group caudal } \\
(n=25)\end{array}$ & p-value \\
\hline $\begin{array}{l}\text { Mean time to rescue } \\
\text { analgesia }\end{array}$ & $5.52 \pm 7.53$ & $4.96 \pm 4.32$ & $0.000 \#$ \\
\hline $\begin{array}{l}\text { Mean total paracetamol } \\
\text { dose requirement }\end{array}$ & $111.40 \pm 138.81$ & $298.40 \pm 170.70$ & $0.0117 *$ \\
\hline
\end{tabular}

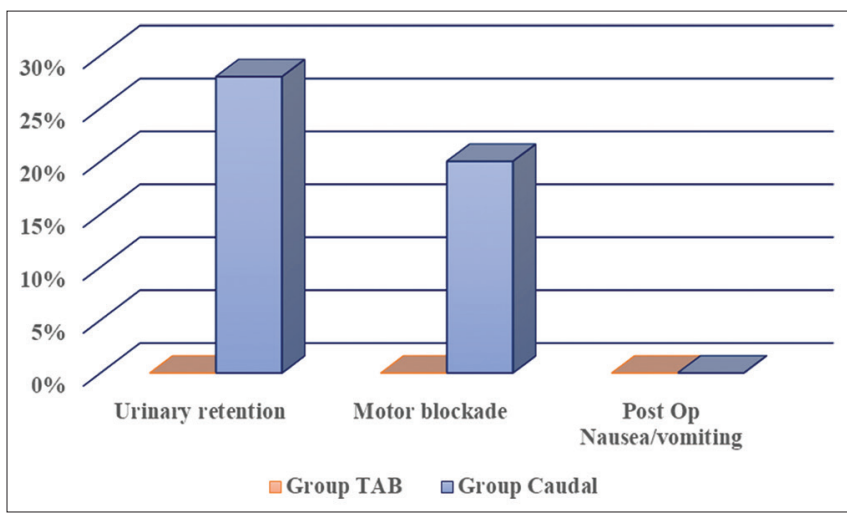

Fig. 1: Post-operative complications among group TAB and group caudal

$12 \mathrm{~h}$ in post-operative period and remained higher thereafter as well.

In accordance with these results, El Fawy and El Gendy [17] reported similar pain scale score between TAP and caudal blocks in children undergoing open pyeloplasty on arrival at the PACU, at the time of discharge from the PACU, and 14 and $22 \mathrm{~h}$ postoperatively. However, they found significantly lower pain scores in the TAP block group compared with the caudal group at other time points postoperatively. They failed to explain this controversy.

Another study by Alsadek et al. [18] reported that TAP block, when compared with caudal, provided low pain scores and less need for rescue analgesics from 6 to $12 \mathrm{~h}$ postoperatively. In their study, most of the children fulfilled the criteria of readiness for home discharge within $6 \mathrm{~h}$ postoperatively and pain assessment at home was done by the parent.

In our study, the time for first rescue analgesic request was found earlier in the CE group (4.96 $\mathrm{h}[\mathrm{SD}=4.32]$ ) as compared to the TAP group in which it was $5.52 \mathrm{~h}(\mathrm{SD}=7.53)$ which was statistically significant. This is in conjunction with a study done by Tobias, in which he demonstrated ultrasound-guided TAP block in 10 pediatric patients between 10 months and 8 years of age, undergoing umbilical and lower abdominal surgeries with $0.3 \mathrm{ml} / \mathrm{kg}$ of $0.25 \%$ bupivacaine and $1: 200,000$ adrenaline [19]. In that, he reported effective analgesia in eight out of 10 patients with the first rescue analgesic request varying from 7 to $11 \mathrm{~h}$.

Cheon et al. [20] who compared caudal block with local infiltration in children undergoing inguinal herniorrhaphy noticed that children in the caudal group did not need rescue analgesic; however, in that study, post-operative pain was assessed for $2 \mathrm{~h}$ only, whereas in our study, assessment was done till $24 \mathrm{~h}$ postoperatively.

It was also apparent from our study that the mean total rescue analgesic requirement for caudal group was $298.40 \mathrm{mg}(\mathrm{SD}=170.70)$ which was significantly higher than the TAP block group in which it was only $111.40 \mathrm{mg}$ (SD=138.81). This is in contrast to the study by Neha and Sharmila [4] in which the difference between the total analgesic requirements in both the groups was not statistically significant. In our study, dexamethasone was used as an additive to local anesthetic which helps in prolonging the effect of analgesia and thereby reduces the total rescue analgesic dose. There are evidences which show that both local effects on nerve fibers and systemic effects of steroids potentiate the analgesic properties of dexamethasone [21]. Studies have shown that dexamethasone when used as an adjuvant to local anesthetics in epidural and spinal anesthesia has prolonged the duration of sensory block [22]. Dexamethasone has also found to be efficacious as an adjuvant in peripheral nerve blocks including TAP block [23]. However, all these studies were largely performed on adult patients with no reference to the pediatric age group.

Furthermore, a meta-analysis comparing caudal block with non-caudal regional techniques for inguinal surgeries in children [24] found that caudal block might be a better analgesic in early and late post-operative periods, but with a significant risk for motor block and urinary retention. Such complications may preclude early discharge for daycase surgeries.

\section{CONCLUSIONS}

Our study showed significant increase in duration of post-operative analgesia among TAP patients with reduced requirement of rescue analgesics and lesser post-operative complications as compared to CE patients.

\section{IMPLICATIONS}

Improved post-operative analgesia with lesser complications in TAP patients.

\section{ACKNOWLEDGMENTS}

I acknowledge and thank to all my coauthors and study participants.

\section{AUTHORS' CONTRIBUTIONS}

All authors have contributed to the preparation of manuscript.

\section{CONFLICTS OF INTEREST}

Nil.

\section{AUTHORS' FUNDING}

Nil.

\section{REFERENCES}

1. Hurley RW, Wu CL. Acute post-operative pain. In: Miller RD, editor. Miller's Anaesthesia. $7^{\text {th }}$ ed. Philadelphia, PA: Churchill Livingstone; 2009. p. 2757-758

2. Bosengberg A. Pediatric regional anaesthesia update. Pediatr Anaesth 2004;14:398-402.

3. Dalens B, Hansanoui A. Caudal anaesthesia in pediatric surgery: Success rate and adverse effects in 750 consecutive patients. Anesth Analg 1989;68:83-9.

4. Neha K, Sharmila A. Comparison of transversus abdominis plane block and caudal block for postoperative analgesia in children undergoing lower abdominal surgery. Int J Sci Res 2015;4:2319-7064

5. Petersen PL, Mathiesen O, Torup H. Dahl JB. The Transversus abdominis plane block: A valuable option for postoperative analgesia? A topical review. Acta Anaesthesiol Scand 2010;54:529-35.

6. Wahba SS, Kamal SM. Analgesic efficacy and outcome of tranversusabdominis plane block versus low thoracic-epidural analgesia after laparotomy in ischaemic heart disease patients. J Anesth 2014;28:517-23.

7. Kadam RV, Wijk VR, Moran JI, Miller D. Epidural versus continuous transverses abdominis plane catheter technique for postoperative analgesia after abdominal surgery. Anaesth Intensive Care 2013;41:476-81.

8. Lissauer J, Mancuso K, Merritt C, Prabhakar A, Kaye AD, Urman RD. Evolution of the transversus abdominis plane block and its role in postoperative analgesia. Best Pract Res Clin Anaesthesiol 2014;28:117-26.

9. El-Dawlatly AA, Turkistani A, Kettner SC, Machata AM, Delvi MB, Thallaj A, et al. Ultrasound-guided transversus abdominis plane block: Description of a new technique and comparison with conventional 
systemic analgesia during laparoscopic cholecystectomy. Br J Anaesth 2009;102:763-7.

10. McDonnell JG, O’Donnell B, Curley G, Heffernan A, Power C, Laffey JG. The analgesic efficacy of transversus abdominis plane block after abdominal surgery: A prospective randomized controlled trial. Anesth Analg 2007;104:193-7.

11. O'Donnell BD, McDonnell JG, McShane AJ. The transversus abdominis plane (TAP) block in open retropubic prostatectomy. Reg Anesth Pain Med 2006;31:91.

12. McDonnell JG, Curley G, Carney J, Benton A, Costello J, Maharaj CH, et al. The analgesic efficacy of transversus abdominis plane block after cesarean delivery: A randomized controlled trial. Anesth Analg 2008;106:186-91.

13. Abdul Jalil RM, Yahya N, Sulaiman O, Wan Mat WR, Teo R, Izaham $\mathrm{A}$, et al. Comparing the effectiveness of ropivacaine $0.5 \%$ versus ropivacaine $0.2 \%$ for transabdominis plane block in providing postoperative analgesia after appendectomy. Acta Anaesthesiol Taiwan 2014;52:49-53

14. Carney J, McDonnell JG, Ochana A, Bhinder R, Laffey JG. The transversus abdominis plane block provides effective postoperative analgesia in patients undergoing total abdominal hysterectomy. Anesth Analg 2008; 107:2056-60.

15. Bonnet F, Berger J, Aveline C. Transversus abdominis plane block: What is its role in postoperative analgesia? Br J Anaesth 2009;103:468-70.

16. de Beer DA, Thomas ML. Caudal additives in children--solutions or problems? Br J Anaesth 2003;90:487-98.

17. El Fawy DM, El Gendy HA. Ultrasound-guided transversus abdominis plane block versus caudal block for postoperative pain relief in infants and children undergoing surgical pyeloplasty. Ains Shams J Anesthesiol 2014;7:177-81

18. Alsadek WM, Al-Gohari MM, Elsonbaty MI, Nassar HM, Alkonaiesy RM. Ultrasound guided TAP block versus ultrasound guided caudal block for pain relief in children undergoing lower abdominal surgeries. Egypt J Anaesth 2015;31:155-60.

19. Tobias JD. Preliminary experience with transversus abdominis plane block for post-operative pain relief in infants and children. Saudi J Anaesth 2009;3:2-6.

20. Cheon JK, Park CH, Hwang KT, Choi BY. A comparison between caudal block versus splash block for postoperative analgesia following inguinal herniorrhaphy in children. Korean J Anesthesiol 2011;60:255-9.

21. Swain A, Deb SN, Sahu S, Samaddar DP. Adjuvants to local anesthetics: Current understanding and future trends. World J Clin Cases 2017;5:307-23.

22. Jebaraj B, Khanna P, Baidya DK, Maitra S. Efficacy of epidural local anesthetic and dexamethasone in providing postoperative analgesia: A meta-analysis. Saudi J Anaesth 2016;10:322-7.

23. Ammar AS, Mahmoud KM. Effect of adding dexamethasone to bupivacaine on transversus abdomins plane block for abdominal hysterectomy: A prospective randomized controlled trial. Saudi J Anaesth 2012;6:229-33.

24. Shanthanna H, Singh B, Guyatt G. A systematic review and metaanalysis of caudal block as compared to noncaudal regional techniques for inguinal surgeries in children. Biomed Res Int 2014;2014:890626. 